\title{
PRÁTICAS DE CUIDADO DE SI NAS CENAS INICIAIS NO BANQUETE DE PLATÃo
}

Self-care practices in first scenes in Plato's Symposium

\section{Felipe Gustavo Soares da Silva ${ }^{1}$}

RESUMO: O presente trabalho trata de analisar duas cenas iniciais do diálogo de Platão, o Simpósio, envolvendo a chegada de Sócrates na casa de Agatão. A proposta é examinar como estas duas cenas sinalizam práticas de cuidado de si na antiguidade e, sobretudo, como antecipam questões que serão imprescindíveis para compreensão da leitura da obra como um todo. Ademais, trata-se de verificar como as práticas podem contribuir no processo do conhecimento através do cuidado de si.

PALAVRAS-CHAVE: Eros; cuidado; Simpósio; autoconhecimento; moderação.

ABSTRACT: This work comes to analyze two initial scenes of Plato's dialogue, the Symposium, involving the arrival of Socrates in Agathon's house. The proposal is to examine how these two scenes indicate care practices themselves in antiquity and especially to anticipate issues that will be invaluable in understanding the reading of the work as a whole. Moreover, it is to check how practices can contribute to the process of knowledge through self-care.

KEYWORDS: Eros; Caution; Symposium; self-knowledge; moderation.

\section{INTRODUÇÃO}

O cuidado de si, noção fundamental no mundo grego, é uma máxima que se impõe como elemento próprio daquela cultura. Trata-se uma maneira de viver, ainda mais, como uma prática cultural, envolve costumes, representando um modo regulador do agir do homem. Nesta maneira de conduzir a própria vida, o Simpósio ${ }^{2}$ testemunha que Platão está inserido, devido às práticas que a própria obra nos atesta, tais como meditações, aconselhamentos, medição quantitativa das

\footnotetext{
${ }^{1}$ Mestrando em Filosofia na UFPE, linha de pesquisa metafísica e ontologia. Licenciado em Filosofia pela UFPE e Bacharel também em Filosofia pela UNICAP. Atua no grupo de pesquisa Dínamis: A filosofia antiga e seus desdobramentos. Desenvolve projeto de pesquisa voltada para leitura do diálogo O banquete, de Platão.

2 Tratamos de escolher a tradução Simpósio e utiliza-la no corpus do trabalho por mais se adequar à descrição da natureza do encontro narrado no diálogo. Para tanto, a tradução principal para leitura do diálogo trata-se de: PLATÃO. Simpósio. Tradução de Carlos Alberto Nunes. - 3a ed. - Belém: ed. UFPA 2011. Pelas normas citaremos: Symp.
} 
refeições e relações, enfim, práticas que devem ser perseguidas como propedêuticas para Excelência.

O cuidado não é uma novidade do pensamento filosófico, apesar de ter nele o seu ponto culminante e não se encontra somente no Platonismo, mas em muitas doutrinas filosóficas, podendo ainda ser encontrado como um tema grego muito anterior às correntes filosóficas que chegaram até nós, o que reforça sua importância para o estudo da Antiguidade.

Olhar para o problema do cuidado, tratado na antiguidade, não quer dizer que ele esteja resolvido, mas, na verdade, a partir das análises que faremos sobre as mais rigorosas e dedicadas práticas do homem grego, o cuidado de si, vemos que esse tema contempla algo que nunca esgotará o debate, pois trata de algo bastante dinâmico na vida humana, o amor, que é na verdade a forma do homem relacionar-se com as coisas, e com o outro, pelo desejo; é problemático amar de qualquer maneira e desejar a tudo e em qualquer medida, visto que o homem quer sempre a melhor formar de viver a vida, mas não pode vive-la de qualquer jeito, o que implica a possibilidade de não alcançar a sua plena realização enquanto homem. Essa nossa tentativa de dar uma resposta ao problema do amor para o ser humano, a partir do pensamento antigo, foi inspirada também a partir do pensamento de Pierre Hadot, em sua obra "O que é a filosofia antiga", segundo ele, "a Filosofia de Platão bem com as filosofias da antiguidade são na verdade um modo de vida" e diante disto reforçamos o nosso pensamento de que é necessário saber o caminho que pode conduzir o homem à realização.

Tratamos de estudar de analisar as cenas iniciais do Simpósio procurando descrever como implicitamente e explicitamente encontramos a noção de um "cuidado de si" bem como o desenrolar de suas práticas.

Tratamos de situar nossa abordagem às relações eróticas, no momento histórico da pederastia ateniense, que tem seu auge e melhor reflexo no período clássico da antiga Grécia e situamos amor e cuidado no contexto da pederastia, onde auxiliou-nos bastante a verificar o perfil do homem grego bem como suas práticas a obra "A homossexualidade grega", 1978, escrita pelo britânico James Dover ${ }^{2}$, onde ele apresenta a questão da pederastia e explora a significação da cultura grega do amor e do erotismo a partir da relação entre homens. As práticas pederásticas refletiam a visão e a prática do homem grego que cultivava uma cultura de auto aprimoramento e de formação do homem a partir da educação. O modelo da pederastia era um processo de formação social que visava à educação dos jovens, a partir da relação entre mestre e discípulo. Tudo isto reforçava a proposta da educação pederástica e pedagógica, num modelo clássico de formação social na história. Desta forma, os elementos históricos que o Simpósio nos apresenta,

${ }^{1}$ HADOT, Pierre. O que é a Filosofia Antiga. $3^{a}$ ed. Loyola, São Paulo, 2008. p.89

2 DOVER, K. J. A homossexualidade na Grécia antiga. Trad. L. S. Krausz. São Paulo: Nova Alexandria, 1994. 
também contribuem para acreditar que seu estudo é fundamental por abordar a questão do amor e do desejo como algo próprio e concreto do ser humano e mostrar como as práticas de cuidado podem ser relacionadas com os ideais filosóficos da Excelência.

O cuidado de si aparece, como tema Socrático e dentro disto, como um tema político, por envolver o homem como um todo em meio aos outros homens, e longe do individualismo, ser o cuidado uma atitude extremamente voltada para o outro e só nele encontrando uma existência plena. O cuidado consistirá, na perspectiva socrático-platônica, fundamentalmente no cuidado da alma: é essa a grande lição que aferimos do imperativo de Sócrates, conhece-te a ti mesmo, que por sua vez, não se distancia do imperativo do mundo grego do cuidado de si.

Ora, costuma-se estudar cuidado de si em Platão a partir do diálogo Alcebíades primeiro, ou até mesmo como tarefa do Sócrates da Apologia, ou como expressão da Soprosine na República. Aqui escolhemos o Simpósio por trazer duas práticas claras em uma linguagem clara que demonstra como Platão em suas obras, refletia a autenticidade do homem grego e testemunhava as ações do mestre Sócrates.

\section{AS CENAS INICIAIS DO DIÁLOGO}

Para demonstrar a relação que supomos existir entre amor e cuidado, chamo-nos atenção duas cenas iniciais do diálogo, que refletem, a nosso ver, uma preparação para o exercício do amor e uma série de recomendações implícitas nos momentos iniciais do Simpósio. Ao mesmo tempo, estas passagens servem como uma introdução a tudo o que vai ser discutido no diálogo. De certa forma, vermos nestas passagens, aquilo que na verdade propomos ser a solução para que se possa estabelecer um verdadeiro amor, um amor que não se pratica de qualquer maneira e um desejo ao qual não se submete de qualquer maneira, mas mediado pelas práticas de si que são diversas, e aqui aparecem já no início do diálogo.

\section{O autoconhecimento}

A etapa que destacamos agora é uma atitude que revela o cuidado como forma de preparação, como antecipação frente às mais diversas situações que o homem se depara. Trazendo a questão para o tema do amor, conforme encontramos no Simpósio, o autoconhecimento é um elemento que prepara o homem para lhe dar com seus desejos, com o amor, com Eros. Sabemos que toda ética platônica busca cuidar dos afetos, das partes desejantes da alma, e a melhor forma de evitar o erro é o conhecimento; sendo assim, a primeira coisa a ser conhecida pelo homem é ele mesmo. A questão já antecipa o fundo epistemológico da abordagem de nosso trabalho. O amor que levará a realização humana e ao conhecimento da 
Verdade, é um amor que transcende o físico e passa pelo elemento do "si mesmo." Este conhecimento de si proporcionará ao homem um posterior conhecimento da Verdade. O Autoconhecimento quer dizer, na ética racionalista de Platão, saber evitar o mal para si mesmo, e na proposta do simpósio, conhecer a fundo os seus desejos além de, é claro, seguir uma séria de regras e ações que conduzem o homem a um trabalho interior, como veremos no próximo ponto.

Vemos no diálogo, bem melhor, nas cenas iniciais, como Sócrates revela-se um homem que se antecedendo aos desafios do amor, procura os momentos "consigo mesmo".

Fizeste muito bem em vir, lhe falou. Mas onde está o teu acompanhante? Agora mesmo vinha atrás de mim; não posso saber o que foi feito dele. Menino, disse Agatão, vai procurar Sócrates e traze-o para cá. E tu, Aristodemo, prosseguiu, reclina-te ao lado de Erixímaco. Então, ainda segundo o seu relato, enquanto um dos meninos o ajudava a lavar os pés para poder deitar-se, entrou outro criado com a notícia de que Sócrates se havia acolhido ao pórtico da casa vizinha, onde se quedara imóvel e de pé. E que, apesar de insistir com ele, acrescentou, não houve jeito de fazê-lo entrar. Que absurdo! Exclamou Agatão; chama-o de novo e não o largues. Nada disso, voltou a falar Aristodemo; deixao em paz. É costume dele; às vezes para em qualquer ponto e não se mexe. Penso que virá logo. Deixai-o; não o perturbeis. ${ }^{1}$

Esses momentos expressam práticas que revelam em que consiste o elemento do autoconhecimento dentro do cuidado de si. O cuidar de si, requer dentre suas práticas, os momentos de reflexão e de autoexame de sua própria ação: esse é exatamente o que nos mostra a personagem Sócrates no momento citado acima. O momento de isolamento de Sócrates, como mostra o próprio testemunho do diálogo, representa uma constante nas ações de Sócrates: isolarse, parar para refletir, e ainda sugere algo bastante simbólico que é o fato do Sócrates não andar necessariamente apressado, mas como que pensando inclusive o próprio andar, e, diante disto, para, reflete, para só depois continuar seu caminho junto com os outros. Apesar deste último simbolismo, a Tradição comumente assim interpreta que a cena em que Sócrates para e reflete é um costume que não pode ser pensado distante das práticas de si, ela é um exemplo claro da proposta e da vivência socrática da auto reflexão, que, é claro, visa ao conhecimento de si, ou ao autoconhecimento. Sendo esta prática imersa no cuidado de si, vemos então no diálogo, a primeira noção daquilo que veremos mais à frente nos outros discursos, que aprofundarão outras práticas e as relacionarão com a erótica.

\section{A moderação}

Depois de demonstrarmos como no diálogo aparece o autoconhecimento como expressão de uma prática do cuidado veremos, agora, uma segunda prática que também é

\footnotetext{
${ }^{1}$ Symp. $175 \mathrm{a}-\mathrm{b}$
} 
recomendada e defendida nas cenas iniciais do Simpósio e que deriva diretamente da primeira: a moderação. Ela é uma expressão clara e evidente do cuidar de si: o cuidado tornará o homem moderado, afinal o cuidar de si mesmo é o modo que o homem encontra para não ser escravo nem de si mesmo. ${ }^{1}$ Para falar da moderação partimos da ideia de que, ela é na verdade um reflexo da cultura do homem grego, e para tanto, faz-se presente no banquete platônico, e chama-nos atenção primeiramente no diálogo, a passagem onde Agatão, à espera de Sócrates, ${ }^{2}$ ordena aos rapazes que serviriam o jantar, que servissem a mesa: "e agora, rapazes, servir a mesa! Sempre fazeis o que entendeis, quando ninguém vos vigia, coisa, aliás, que não é dos meus hábitos.” ${ }^{3}$

A ação de Agatão tem a nosso ver uma dupla sugestão para um comportamento louvável: em primeiro lugar é uma advertência para os próprios serventes das mesas, que teriam um comportamento duplo, perante as pessoas que o vigiassem e em esfera privada ou pelo menos sem estar na presença de alguém: "sempre fazeis o que entendeis, quando ninguém os vigia."”4. E, em segundo lugar, e não menos importante, para o próprio Agatão, que em sua fala sugere que seus hábitos louváveis tanto no âmbito público quanto no íntimo, "coisa aliás que não é dos meus hábitos" "5 Agatão nos dá a entender que a virtude deve ser praticada por si mesma, e não apenas na presença dos outros como aparência ou superficialidade, como atitude forçada e aparente; esta ideia será retomada mais a frente no próprio Simpósio, no discurso de Fedro, onde ele fala de um amor que inspira as mais diversas ações nobres, e que o amado seria tomado pelo sentimento de vergonha se apanhado em uma ação vil diante de seu amante do que diante de qualquer outra pessoa. ${ }^{6}$ Agatão antecipa o que podemos interpretar perante o discurso posterior de Fedro: a virtude deve ser procurada por si mesma e não apenas como aparência ${ }^{7}$, o amor irá inspirar a virtude em si mesma, através do "cuidar de si”, através de práticas que unificam as ações do homem na vida pública e na vida privada. Apesar de Fedro, em seu discurso, falar de um amor e um cuidado aparente e não verdadeiro, a sugestão que ele nos dá é precisamente a mesma que Agatão relata: Fedro fala de como se dá o amor aparente, já Agatão fala sobre o verdadeiro e ainda mais, a partir de sua própria experiência. Ele relata que não é de seu hábito agir de maneira diferente em nenhum momento ${ }^{8}$, ou seja, sua virtude e seu cuidado é constante

\footnotetext{
${ }^{1}$ VERNANT, Jean Pierre. Individu, la mort, l'amour. L' soi-mêne et l' autre em grèce ancienne. Paris, galimard, 1996. p.229

${ }^{2}$ Symp.. 175b

${ }^{3}$ Idem

${ }^{4}$ Idem

${ }^{5}$ Idem

${ }^{6}$ Symp. 178e

${ }^{7}$ Cf. Discurso de Fedro, no Simpósio em 178 d-e quando fala do sentimento de vergonha que o amado sente ao cometer um gesto condenável diante de seu amante.

8 Symp. 175b
} 
não é aparente e dependente do outro, e neste sentido livre (eleútheros) ${ }^{1}$ e, portanto, a moderação é atingida por ele através do cuidar de si verdadeiro e constante, preocupado com ser e não parecer diante dos outros e de si mesmo, principalmente.

Por fim, a moderação da comida e, sobretudo, da bebida, conforme recomendado pelo médico Erixímaco, antes do início do banquete nos conduz a uma questão que é explícita para o nosso tema, pois traz a moderação como dever ou tarefa de todos os representantes que iam discursar: é de comum acordo que resolvem não beber, num primeiro momento. Todas estas preocupações antecedem os discursos do amor, e nos indicam que, a virtude deve fazer parte do homem, neste trecho, $\mathrm{O}$ Banquete ${ }^{2}$ sugere duas lições que derivam da decisão de não beber:

Em primeiro lugar, Pausânias propõe que os presentes não bebam, ou que evitem os excessos porque, segundo ele "Nós sempre fomos muitos fracos" ${ }^{3}$. Podemos dizer que a sugestão de Pausânias é, em primeiro lugar, expressão do cuidado e da observação de suas próprias condições e limitações frente aos desejos do apetite e para tal, tentam ser moderados em suas ações; em segundo lugar, a confirmação de Aristófanes, "fizeste bem, Pausânias, em propor que nos esforcemos por todos os meios para evitar excessos" "4 sugere que a busca da moderação, pelo cuidado, consiste em uma decisão firme e em uma atitude interior, um esforço do próprio homem para ser então, moderado. Quando Pausânias cita Sócrates "Não falo de Sócrates, para ele tanto faz: beber ou abster-se" ${ }^{\prime 5}$ ressalta de maneira positiva o que seria o modelo ideal de moderação para eles. Caso Sócrates quisesse beber, o faria de maneira moderada, por isso tanto faz beber ou não.

Em segundo lugar, a decisão corroborada por Aristófanes de que os convivas não bebam é uma expressão clara do cuidado e da moderação que é também uma reflexão sobre a própria conduta, a partir de sua técnica $(\tau \dot{\varepsilon} \chi \vee \eta)$, sobre seus próprios hábitos, utiliza os conhecimentos médicos, mais a frente no diálogo, para relacionar a filosofia e a medicina, sugerindo um cuidado com o corpo, e já adianta essa questão quando fala que é da medicina que ele tem autoridade para falar sobre a moderação no beber "razão porque nem pretendo recomeçar a beber nem aconselho os outros a fazerem o mesmo, principalmente quem ainda se ressente dos excessos de ontem." Ora, o cenário do banquete se dá após um dia de bebedeira, um dia de excessos e imoderações na bebida e para tal, é atitude do "cuidar de si" a reflexão sobre a própria conduta. Visto assim, podemos ver o moderado como aquele que apesar de um possível excesso cometido, sabe evitar que o excesso se torne hábito.

${ }^{1}$ Cf. ARAÚJO JÚNIOR, 2012.

${ }^{2}$ Leia-se sobre esta grafia o jantar e não a obra.

${ }^{3}$ Symp. 176b

${ }^{4}$ Symp 176b

${ }^{5}$ Symp. 176b

${ }^{6}$ Symp., 176d. 


\section{CONCLUSÃO}

Cuidar de si é uma máxima e uma prática antiga que reflete o perfil prático do homem na antiguidade e nos leva a refletir a importância que era dada pelos antigos ao trabalho pedagógico que não dispensava o papel do próprio educando na sua própria formação. Em todas ações e em suas mais diversas formas de relacionamento, o homem grego preocupava-se com a maneira de fazer cada coisa de forma que a ação não lhe fizesse mal nem ao corpo nem à alma mas contribuísse para o progresso nos valores morais e na virtude. Desta maneira, procuramos em nosso trabalho verificar como estas preocupações estavam presentes no diálogo de Platão, Simpósio, ou Banquete, e para isso, não precisamos aprofundar os discursos, mas, nas cenas iniciais, já encontramos pistas da preocupação de Platão em, como grego autêntico, elaborar um testemunho e manual sobre como o cuidado de si deveria estar presente sobretudo, nas questões do amor.

O diálogo nos possibilita, através da análise das cenas inicias, refletir como o autoconhecimento e a moderação são etapas do cuidado que perfazem as práticas de olhar para si e conhecer-se. Sabemos que a ideia de bem perfaz todo o percurso e busca pela Verdade, aqui, essa busca recebe um contributo importantíssimo para o debate, pois, antes de conhecer as coisas ao seu redor, o homem deveria conhecer a si mesmo, conforme a mensagem Socrática do “conhece-te a ti mesmo." Conhecer-se a si mesmo é uma etapa preliminar, mas não fácil de poder conhecer as outras coisas. Num diálogo que trata sobre o amor, vemos então, já nas cenas iniciais, que há uma relação profunda entre amor e conhecimento, visto que amos implicam a prática do cuidado, o amor à sabedoria, à ideia de beleza, só é possível pela prática do cuidado. Ou seja, implica que um amor ordenado, conforme o Simpósio nos apresenta, possibilita então um auxílio na busca do conhecimento pelas práticas do cuidado de si, noutras palavras, o homem que almeja conhecer todas as coisas tem como tarefa preliminar o conhecimento de si mesmo para então poder ascender ao conhecimento do que está ao seu redor. 


\section{REFERÊNCIAS}

ARAÚJO JÚNIOR. Anastácio. Borges de. “Os sentidos da Eleuthería na República de Platão". Archai n. 9, jul-dez 2012, pp. 27-36.

BRAVO, F. As ambiguidades do prazer: ensaios sobre o prazer na Filosofia de Platão. São Paulus, Paulus, 2009.

CASERTANO, G. Il, Piacere, l'amore e la morte nelle dottrine dei presocratici. Napoli, 1983.

DOVER, K. J. A homossexualidade na Grécia antiga. Trad. L. S. Krausz. São Paulo: Nova Alexandria, 1994.

FERRARI, F. “Eros, Paideia e Filosofia: Sócrates entre Diotima e Alcibíades”. Archai n. 9, juldez 2012, pp. 65-116

Platonic Love, In. R. kraut (ed.), The Cambridge Companion to Plato.1992

FOULCAULT, Michel. História da sexualidade. Vol. 3 O cuidado de si. $8^{a}$ ed. Graal. São Paulo, 2005.

HADOT, Pierre. O que é a Filosofia Antiga.3a ed. Loyola, São Paulo, 2008.

JAEGER, Werner. Paideia: a formação do homem grego. $5^{a}$ edição. Martins fontes São Paulo, 2011.

PESSANHA, José Américo Motta. "Platão: as várias faces do amor”. In: Os Sentidos da Paixão. São Paulo: CIA. das Letras, 1989.

PLATÃO. Simpósio. Tradução de Carlos Alberto Nunes. - 3ª ed. - Belém: ed. UFPA 2011. Fedro. Trad. de Carlos Alberto Nunes. Belém. Universidade Federal do Pará, 1975

ROBIN, Léon. La théorie Platonicienne de L'amour. 3.ed. Paris, Presses Universitáires de France, 1964.

VERNANT, Jean Pierre. Individu, la mort, l'amour. L' soi-mêne et l'autre em grèce ancienne. Paris: Galimard, 1996. 